\title{
Management of early gastric cancer meeting criteria for endoscopic resection: US population-based study
}

\section{다)(우우}

\section{Authors}

Mohamed Barakat ${ }^{1}$, Daryl Ramai ${ }^{2}$, Derrick Cheung ${ }^{1}$, Mohamed M. Abdelfatah ${ }^{3}$, Mohamed O. Othman ${ }^{4}$, David L. CarrLocke $^{5}$, Douglas G. Adler 6

Institutions

1 Division of Gastroenterology and Hepatology, The Brooklyn Hospital Center, Brooklyn, New York, United States

2 Department of Internal Medicine, The Brooklyn Hospital Center, Brooklyn, New York, United States

3 Division of Gastroenterology and Hepatology, University of Alabama, Birmingham, Alabama, United States

4 Division of Gastroenterology and Hepatology, Baylor College of Medicine, Houston, Texas, United States

5 Division of Gastroenterology and Hepatology, New York Presbyterian, New York, New York, United States

6 Division of Gastroenterology and Hepatology, Utah University, Salt Lake City, Utah, United States

submitted 2.12.2020

accepted after revision 8.3.2021

\section{Bibliography}

Endosc Int Open 2021; 09: E989-E993

DOI 10.1055/a-1478-3281

ISSN 2364-3722

(c) 2021. The Author(s).

This is an open access article published by Thieme under the terms of the Creative Commons Attribution-NonDerivative-NonCommercial License, permitting copying and reproduction so long as the original work is given appropriate credit. Contents may not be used for commercial purposes, or adapted, remixed, transformed or built upon. (https://creativecommons.org/licenses/by-nc-nd/4.0/)

Georg Thieme Verlag KG, Rüdigerstraße 14,

70469 Stuttgart, Germany
Corresponding author

Douglas G. Adler MD, FACG, AGAF, FASGE, Division of

Gastroenterology and Hepatology, University of Utah School

of Medicine, Huntsman Cancer Center, Salt Lake City, Utah, USA

Fax: +1-801-581-8007

Dougraham2001@gmail.com

\section{ABSTRACT}

Background and study aims The goal of this study was to assess surgical resection (SR) of early gastric cancer (EGC) fitting Japanese Gastric Cancer Association (JGCA) endoscopic resection (ER) criteria.

Patients and methods We analyzed EGC data from the national Surveillance, Epidemiology, and End Results (SEER) database from 2010 to 2015.

Results A total of 2219 EGC cases were identified (1074 T1a and $1145 \mathrm{~T} 1 \mathrm{~b})$. Of them, 409 met absolute criteria, 219 met expanded 1, 529 expanded 2, and 229 expanded 3. 259 lesions were treated endoscopically while 1007 were surgically resected $(20.5 \%$ vs $79.5 \%, P=0.0001)$. Temporal analysis showed that the frequency of ER steadily increased while SR proportionally decreased during the study period. Cox proportion regression analysis adjusting for confound variables (including age, gender, and race) showed no significant difference in the risk of mortality following either surgery or endoscopy.

Conclusions EGC can be safely treated with ER. However, EGC meeting JGCA ER criteria is largely treated with SR in the United States.

\section{Introduction}

Endoscopic resection (ER) for early gastric cancer (EGC) is the primary treatment modality for lesions fulfilling the absolute and expanded criteria developed by the Japanese Gastric Cancer Association [1]. However, there are limited availability of endoscopists who can perform endoscopic mucosal resection (EMR) and endoscopic submucosal dissection (ESD). Gastrectomy most often is performed in these cases, which is associated with an increase in morbidity and mortality [2]. The aim of this study was to evaluate the rates of inappropriate surgical resection of EGC fitting JGCA absolute and expanded ER criteria that could have potentially been removed by endoscopy. We also evaluate temporal trends comparing the utilization of surgical and endoscopic resection of EGC. 
- Table 1 Study characteristics. Clinical variables included tumor location and pathological variables included tumor size, stage, and grade

\begin{tabular}{|c|c|}
\hline T1a variables & n (\%) \\
\hline \multicolumn{2}{|l|}{ Patient sex } \\
\hline - Male & $653(60.8 \%)$ \\
\hline - Female & $421(39.2 \%)$ \\
\hline \multicolumn{2}{|l|}{ Tumor site } \\
\hline - Cardia & $343(31.9 \%)$ \\
\hline - Fundus & $28(2.6 \%)$ \\
\hline - Body & $100(9.3 \%)$ \\
\hline - Antrum & $319(29.7 \%)$ \\
\hline - Pylorus & $37(3.4 \%)$ \\
\hline - Lesser curvature & $108(10.1 \%)$ \\
\hline - Greater curvature & $39(3.6 \%)$ \\
\hline - Overlapping & $34(3.2 \%)$ \\
\hline - Unspecified & $66(6.1 \%)$ \\
\hline \multicolumn{2}{|l|}{ Race } \\
\hline - Asian/Pacific & $240(22.3 \%)$ \\
\hline - White & $701(65.3 \%)$ \\
\hline - American Indian & $6(1 \%)$ \\
\hline - Black & $117(10.9 \%)$ \\
\hline - Unknown & $10(1 \%)$ \\
\hline \multicolumn{2}{|l|}{ Tumor grade } \\
\hline - Well differentiated & $255(23.7 \%)$ \\
\hline - Moderately differentiated & $409(38.1 \%)$ \\
\hline - Poorly differentiated & $387(36.0 \%)$ \\
\hline - Undifferentiated & $23(2.1 \%)$ \\
\hline \multicolumn{2}{|l|}{ Size } \\
\hline . $<10 \mathrm{~mm}$ & $386(35.9 \%)$ \\
\hline - $10-20 \mathrm{~mm}$ & $297(27.7 \%)$ \\
\hline - $20-30 \mathrm{~mm}$ & $(15.9 \%)$ \\
\hline . $>30 \mathrm{~mm}$ & $220(20.5 \%)$ \\
\hline
\end{tabular}

\section{Patients and methods}

Data on early gastric cancer was collected from the Surveillance, Epidemiology, and End Results (SEER) database from 2010 to 2015. Data were collected from 18 registries, which, in aggregate, represents nearly $28 \%$ of the US population. Exclusion criteria included: entries with unknown tumor characteristics, inadequate information on tumor staging and treatment options. The demographic variables of interest were patient sex, age at diagnosis, race, and year of diagnosis. Race was recorded as White, Black, American Indian/Alaska Native,
- Table 2 Lymph node metastasis by expanded and absolute criteria for patients who underwent intervention

\begin{tabular}{|l|l|l|l|}
\hline Indication & $\begin{array}{l}\text { Endoscopic } \\
\text { resection }\end{array}$ & $\begin{array}{c}\text { Surgical } \\
\text { resection }\end{array}$ & P value \\
\hline $\begin{array}{l}\text { Absolute }(\mathrm{T} 1 \mathrm{a} \text {, differen- } \\
\text { tiated, }<2 \mathrm{~cm})\end{array}$ & $100 / 386$ & $286 / 386$ & 0.0001 \\
\hline $\begin{array}{l}\text { Expanded \#1 (T1a, dif- } \\
\text { ferentiated, }>2 \mathrm{~cm})\end{array}$ & $21 / 170$ & $149 / 170$ & 0.0001 \\
\hline $\begin{array}{l}\text { Expanded \#2 (T1a, dif- } \\
\text { ferentiated, <3 cm) }\end{array}$ & $118 / 496$ & $378 / 496$ & 0.0001 \\
\hline $\begin{array}{l}\text { Expanded \#3 (T1a, un- } \\
\text { differentiated, }<2 \mathrm{~cm})\end{array}$ & $20 / 214$ & $194 / 214$ & 0.0001 \\
\hline
\end{tabular}

and Asian or Pacific Islander. Clinical variables included tumor location. Pathological variables included tumor size, stage, and grade. The American Joint Committee on Cancer (AJCC) 2004 staging criteria was utilized. Tumor size was categorized as $<10 \mathrm{~mm}, 10$ to $20 \mathrm{~mm}, 20$ to $30 \mathrm{~mm}$, and $>30 \mathrm{~mm}$.

EGC fulfilling the Japanese Gastric Cancer Association (JGCA) absolute and expanded criteria (version 3) were analyzed. We performed subgroup analysis comparing the rate of surgical and endoscopic resection for each criterion. We performed temporal analysis to observe the rate of surgical and endoscopic resection over time (from 2010 to 2015). Additionally, Kaplan-Meier survival curves were estimated to compare mortality of surgical and endoscopic resection. Log-rank tests were performed to determine statistical significance. Cox proportion regression analysis was performed to control for confound variables.

IBM SPSS Statistics was used for all statistical analysis. Statistical significance was set at $P<0.05$. SEER data are publicly available, and all patient information is de-identified; therefore, the current study was deemed to be exempt from institutional review board approval.

\section{Results}

Initially, 161,854 gastric cancers were found, 1074 EGC T1a lesions met inclusion criteria. T1b lesions $(n=1145)$ (JGCA expanded 4 criteria) were not included as it is not an indication for ER ( $\triangleright$ Table 1). Median age of patients among each criterion was comparable (absolute criteria was $71 \pm 12$ years of age, expanded 1 was $72 \pm 11$ years, expanded 2 was $71 \pm 11$ years, and expanded 3 was $71 \pm 12$ years, and expanded 4 was $71 \pm 12$ years). There were 409 lesions fulfilling the absolute criteria (T1a, well differentiated $<2 \mathrm{~cm}$ ). From this cohort, 386 underwent resection; 100 (26\%) lesions were treated endoscopically, and 286 (74\%) lesions were treated surgically $(P=0.0001)$.

There were 219 lesions fulfilling the expanded criteria 1 (T1a, well differentiated, $>2 \mathrm{~cm}$ ). From this cohort, 170 underwent resection; 21 (12\%) lesions were treated endoscopically, and $149(88 \%)$ lesions were treated surgically $(P=0.0001)$. Of the lesions, 529 fulfilled the expanded criteria 2 (T1a, differentiated, $<3 \mathrm{~cm}$ ). From this cohort, 496 underwent resection; 118 


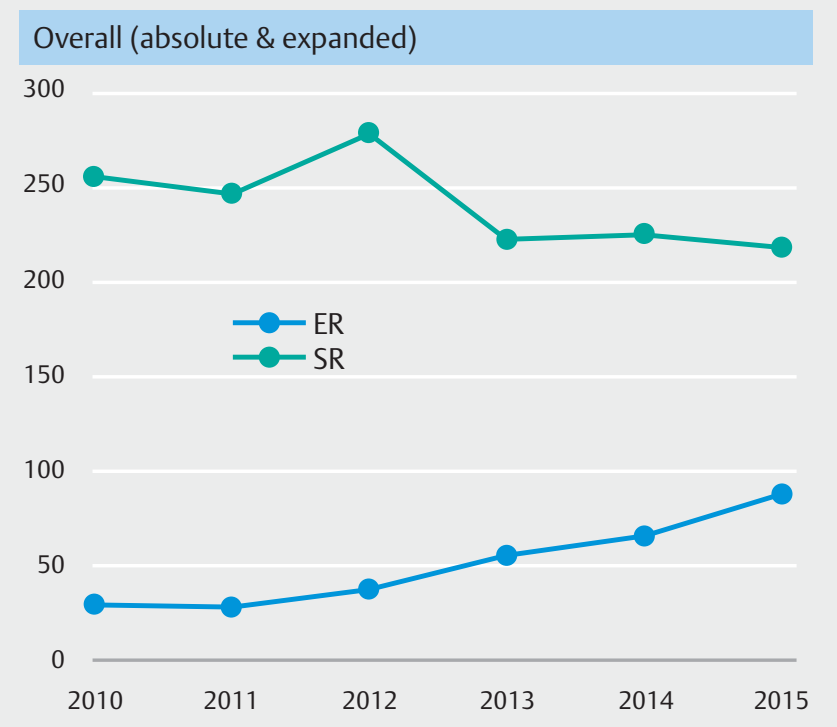

\section{Absolute criteria}

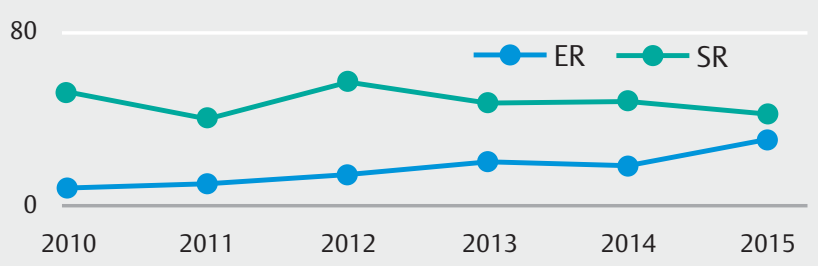

Expanded criteria



- Fig. 1 Trend of surgical resection (SR) and endoscopic resection (ER) according to absolute and expanded criteria.

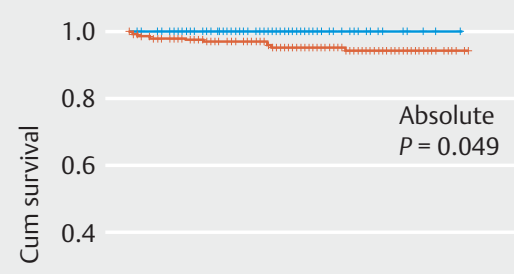

0.2

$$
0
$$
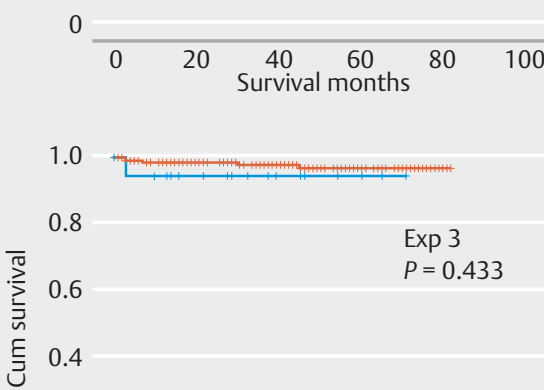

0.2

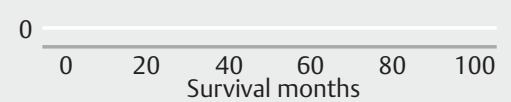

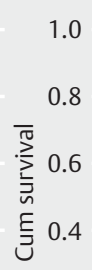

0.2

$$
0
$$
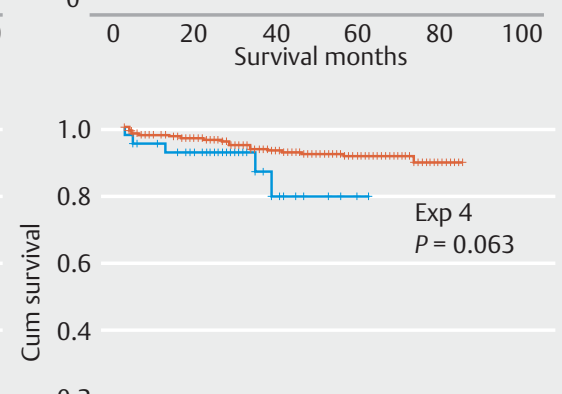

0.2

0

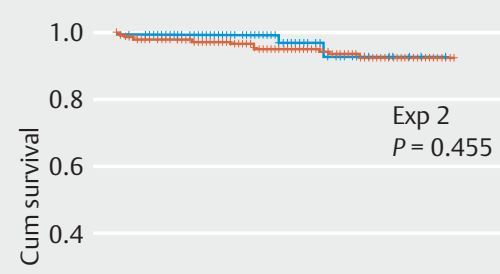

0.2

\section{+ Endoscopy}

+ Surgery

- Fig. 2 Survival analysis of surgical resection (SR) and endoscopic resection (ER) according to absolute and expanded criteria.

(24\%) lesions were treated with endoscopic resection and 378 (76\%) lesions were treated surgically $(P=0.0001)$.

There were 229 lesions fulfilling expanded criteria 3 (T1a, undifferentiated, $<2 \mathrm{~cm}$ ). From this cohort, 214 underwent resection; 20 (9\%) lesions were treated endoscopically, and 194 ( $90 \%)$ lesions were treated surgically $(P=0.0001)$ ( Table 2$)$. Overall, 259 lesions were treated endoscopically while 1007 were surgically resected $(20.5 \%$ vs $79.5 \%, P=0.0001)$. Tumors were more likely to be endoscopically resected if they met the absolute criteria (26\%) compared to expanded 1 (14\%), expanded 2 (24\%), and expanded 3 (9\%).

Temporal analysis from 2010 to 2015 showed that the frequency of ER steadily increased and has approximately tripled (> Fig.1). This increase was largely seen in the absolute criteria 
- Table 3 Cox proportion regression analysis of absolute and expanded criteria.

\begin{tabular}{|c|c|c|c|c|c|c|c|c|c|c|c|c|}
\hline & \multicolumn{3}{|c|}{ Absolute } & \multicolumn{3}{|c|}{ Expanded 1} & \multicolumn{3}{|c|}{ Expanded 2} & \multicolumn{3}{|c|}{ Expanded 3} \\
\hline & $\begin{array}{l}\text { Hazard } \\
\text { Ratio }\end{array}$ & $95 \% \mathrm{Cl}$ & $P$ & $\begin{array}{l}\text { Hazard } \\
\text { Ratio }\end{array}$ & $95 \% \mathrm{Cl}$ & $P$ & $\begin{array}{l}\text { Hazard } \\
\text { Ratio }\end{array}$ & $95 \% \mathrm{Cl}$ & $P$ & $\begin{array}{l}\text { Hazard } \\
\text { Ratio }\end{array}$ & $95 \% \mathrm{Cl}$ & $P$ \\
\hline \multicolumn{13}{|l|}{ Age } \\
\hline $\begin{array}{l}\text { - Continu- } \\
\text { ous }\end{array}$ & 1.04 & $\begin{array}{l}0.985- \\
1.103\end{array}$ & 0.152 & 1.02 & $\begin{array}{l}0.964- \\
1.085\end{array}$ & 0.456 & 1.04 & $\begin{array}{l}0.996- \\
1.087\end{array}$ & 0.078 & 1.06 & $\begin{array}{l}0.972- \\
1.164\end{array}$ & 0.181 \\
\hline \multicolumn{13}{|l|}{ Sex } \\
\hline - Male & \multicolumn{3}{|c|}{ Reference } & \multicolumn{3}{|c|}{ Reference } & \multicolumn{3}{|c|}{ Reference } & & \multicolumn{2}{|c|}{ Reference } \\
\hline - Female & 1.05 & $\begin{array}{l}0.325- \\
3.419\end{array}$ & 0.930 & 0.16 & $\begin{array}{l}0.020- \\
1.338\end{array}$ & 0.091 & 0.55 & $\begin{array}{l}0.207- \\
1.465\end{array}$ & 0.232 & 2.04 & $\begin{array}{l}0.368- \\
11.335\end{array}$ & 0.414 \\
\hline \multicolumn{13}{|l|}{ Race } \\
\hline - White & \multicolumn{3}{|c|}{ Reference } & \multicolumn{3}{|c|}{ Reference } & \multicolumn{3}{|c|}{ Reference } & & \multicolumn{2}{|c|}{ Reference } \\
\hline - Black & - & - & 0.975 & 2.21 & $\begin{array}{l}0.449- \\
10.855\end{array}$ & 0.330 & 1.06 & $\begin{array}{l}0.236- \\
4.719\end{array}$ & 0.943 & 10.62 & $\begin{array}{l}1.837- \\
61.347\end{array}$ & 0.008 \\
\hline $\begin{array}{l}\text { - Asian/ } \\
\text { Pacific } \\
\text { Islander }\end{array}$ & 11.58 & $\begin{array}{l}1.345- \\
99.743\end{array}$ & 0.026 & - & - & 0.000 & 8.49 & $\begin{array}{l}0.998- \\
72.208\end{array}$ & 0.050 & - & - & 0.978 \\
\hline $\begin{array}{l}\text { Ameri- } \\
\text { can In- } \\
\text { dian/ } \\
\text { Alaska } \\
\text { Native }\end{array}$ & 0.44 & $\begin{array}{l}0.095- \\
2.074\end{array}$ & 0.302 & 0.76 & $\begin{array}{l}0.176- \\
3.294\end{array}$ & 0.716 & 0.818 & $\begin{array}{l}0.288- \\
2.320\end{array}$ & 0.705 & - & - & 0.996 \\
\hline \multicolumn{13}{|l|}{ Intervention } \\
\hline $\begin{array}{l}\text { - Endos- } \\
\text { copy }\end{array}$ & \multicolumn{3}{|c|}{ Reference } & \multicolumn{3}{|c|}{ Reference } & \multicolumn{3}{|c|}{ Reference } & \multicolumn{3}{|c|}{ Reference } \\
\hline - Surgery & $25.9 \mathrm{e} 4$ & $\begin{array}{l}0.000- \\
2.7 \mathrm{e} 213\end{array}$ & 0.959 & 0.28 & $\begin{array}{l}0.070- \\
1.086\end{array}$ & 0.065 & 1.72 & $\begin{array}{l}0.498- \\
5.964\end{array}$ & 0.390 & 1.02 & $\begin{array}{l}0.095- \\
10.917\end{array}$ & 0.989 \\
\hline
\end{tabular}

( $3 x$ increase in ER) compared to the expanded criteria (2x increase in ER). There was a concomitant and proportional decrease in $S R$.

Kaplan-Meier estimations showed that endoscopic resection was associated with lower mortality compared to surgery for lesions fulfilling the absolute criteria $(P=0.049)$. Surgery was associated with lower mortality compared to endoscopic resection for expanded 1 lesions $(P=0.049)$. Endoscopic resection was comparable to surgical resection for expanded 2 and 3 lesions $(P>0.05)$ ( $\mathbf{F i g . 2}$ ). However, Cox proportion regression analysis adjusting for confound variables (including age, sex, and race) showed no significant difference in the risk of mortality following either surgery or endoscopy (\ Table 3 ).

\section{Discussion}

In this study, we used a national cancer registry to identify patients diagnosed with EGC. We demonstrate that EGC is being treated predominately via surgical resection despite meeting criteria for endoscopic resection. This trend was consistent with absolute criteria as well as expanded criteria 1 through 3.

Our report shows significant underutilization of ER. ER has been recommended by the Japanese Gastric Cancer Association
(JGCA) and National Cancer Center (NCC) for the treatment of EGC [1]. The smaller size of lesions fulfilling the absolute criteria compared to the size of lesions fulfilling the expanded criteria lesions may account for the higher frequency of endoscopic resection in the absolute criteria group.Smaller lesions are usually confined to the mucosa and as a result often can be readily resected via EMR. Lesions belonging to the expanded criteria are larger and typically require ESD. ESD is not commonly practiced and requires significant advanced training [3].

Our study results are in line with data from previously published Western cohorts and confirms that Japanese criteria are applicable in the United States and that endoscopic resection is a viable solution for patients with early gastric cancer $[4,5]$. Furthermore, our survival analysis and cox regression analysis (adjusting for confound variables) demonstrated comparable outcomes following endoscopic and surgical resection of EGC which supports the use of endoscopy in the United States. In Asia, due to the increasing incidence of EGC, national screening programs have been implemented, which has led to the widespread use of ER and improved survival outcomes [6-8]. Multiple cohorts from Asia have demonstrated similar long-term outcomes between ER and surgical resection [7]. 
Nevertheless, certain limitations must be acknowledged. The limited availability of data from the SEER database is the main drawback. Factors including ulcer status, tumor budding, and lymphovascular invasion were not available for analysis. However, we believe this report demonstrates significant trends in the management of EGC.

\section{Conclusions}

In conclusion, endoscopic resection of EGC is safe and effective for treating EGC but remains underutilized in the United States. Temporal analysis shows an increasing trend of ER for all criteria, with a concomitant decline in surgery as endoscopic techniques are adopted and practiced more broadly.

\section{Competing interests}

The authors declare that they have no conflict of interest.

\section{References}

[1] Japanese Gastric Cancer Association. Japanese gastric cancer treatment guidelines 2010 (ver. 3). Gastric Cancer 2011; 14: 113-123

[2] Bonenkamp JJ, Hermans J, Sasako $M$ et al. Extended lymph-node dissection for gastric cancer. N Engl J Med 1999; 340: 908-914

[3] Wang AY, Draganov PV. Training in endoscopic submucosal dissection from a Western perspective. Tech Gastrointest Endosc 2017; 19: 159-169

[4] Tate D], Klein A, Sidhu M et al. Endoscopic submucosal dissection for suspected early gastric cancer: absolute versus expanded criteria in a large Western cohort (with video). Gastrointest Endosc 2019; 90: 467-479.e4

[5] Probst A, Schneider A, Schaller T et al. Endoscopic submucosal dissection for early gastric cancer: are expanded resection criteria safe for Western patients? Endoscopy 2017; 49: 855-865

[6] Abdelfatah MM, Barakat M, Othman MO et al. The incidence of lymph node metastasis in submucosal early gastric cancer according to the expanded criteria: a systematic review. Surg Endosc 2019; 33: 26-32

[7] Abdelfatah MM, Barakat M, Ahmad D et al. Long-term outcomes of endoscopic submucosal dissection versus surgery in early gastric cancer: a systematic review and meta-analysis. Eur J Gastroenterol Hepatol 2019; 31: 418-424

[8] Zhang X, Li M, Chen S et al. Endoscopic screening in Asian countries is associated with reduced gastric cancer mortality: a meta-analysis and systematic review. Gastroenterology 2018; 155: 347-354 